\title{
Educaçáo Física na estratégia Saúde da Família: \\ ferramenta didática para os programas de Hipertensão Arterial Sistêmica e Diabetes Mellitus
}

\author{
Physical education family's health strategy: \\ teaching tool for programs and systemic arterial hipertension and Diabetes Mellitus
}

\author{
Márcia Ribeiro Braz ${ }^{1}$ \\ Éril Imil Viana Farani ${ }^{1}$ \\ Adilson da Costa Filho ${ }^{1}$
}

\section{Resumo}

Este estudo consiste na elaboração de uma ferramenta computacional voltada ao docente e discente da área de Educação Física, com foco na atuação deste profissional na Estratégia Saúde da Família. A informática vem sendo introduzida na educação em ritmo acelerado, obrigando educadores e educandos a familiarizarem-se com essa tecnologia. A pesquisa teve como objetivo o desenvolvimento de uma multimídia interativa denominada "Atividade Física nos Programas de Hipertensão Arterial Sistêmica e Diabetes Mellitus na Estratégia Saúde da Família”. A metodologia adotada foi a pesquisa bibliográfica que fundamentou a elaboração do CD-ROM que utiliza recursos multimídias, sendo composto por quatro tópicos: Hipertensão Arterial Sistêmica, Diabetes Mellitus e Obesidade; protocolo de intervenção e um teste avaliativo. Conclui-se que a multimídia interativa com interface gráfica é um instrumental didático-pedagógico que permite o acesso a um grande número de informações por meio de textos, gráficos e imagens, favorecendo o processo de ensino-aprendizagem.

Palavras-chave: Educação física, multimídia interativa, Estratégia Saúde da Família.

\section{Abstract}

This study consist in the elaboration of a computing tool directed to the teachers and students acts at the area such Physical Education. It has focus in the acting this professional in the Family's Health Strategy. The information technology has been introduced to the education in accelerated rhythm; it is compelling teachers and students to get acquainted themselves with that technology. The research has had like a purpose the development of an interactive multimedia called "Physical Activity in the Systemic Arterial Hypertension's Programs and Diabetes Mellitus in the Family's Health Strategy". The methodology has been used is the bibliographic research that it was the base on elaboration of CD-ROM. The CD-ROM contains multimedias resources and it is divided into four main points: Systemic Arterial Hypertension, Diabetes Mellitus and obesity, intervention record and a valuated test. Therefore, the interactive multimedia with this graphic interface is a didactic-pedagogic implement that permits the access to the greater part of information by means of texts, graphics and images. That collaborates to the teaching-learning process.

Keywords: Physical Education, interactive multimedia, Family's Health Strategy

\footnotetext{
${ }^{1}$ Centro Universitário de Volta Redonda/ Mestrado Profissional em Ensino de Ciências da Saúde e do Meio Ambiente
} 


\section{CONSIDERAÇÓES INICIAIS}

O conhecimento produzido acerca da atividade física (AF) e saúde, poucas vezes é colocado e aplicado a serviço da sociedade. Acreditamos que talvez esse fato perpasse por vários motivos, dentre eles: o desconhecimento da comunidade sobre a importância do profissional de educação física (EF), o que acaba influenciando na falta de interesse da população em cobrar das autoridades públicas a sua atuação no sistema de saúde. Na concepção de Bagrichevsky (2007), um outro motivo para este desconhecimento do profissional de EF, seria a necessidade de discutir possibilidades para viabilizar um nível de criticidade adequado na formaçáo de professores de EF, a fim de que os mesmos possam compreender e intervir no campo da saúde coletiva, sobretudo dentro da Estratégia Saúde da Família (ESF), como educadores e agentes promotores de conhecimentos e práticas corporais éticas em saúde, que respeitam e consideram a diversidade socioeconômica e cultural em suas intervençôes populacionais.

A partir da experiência do pesquisador de sete anos como docente do curso de Educação Física do Centro Universitário de Volta Redonda - UniFOA, percebeu-se a existência de uma lacuna na grade curricular do graduado em EF,no que tange a inserção do profissional de EF na ESF, assim como suas ações neste programa de governo. Apesar do curso citado acima, ter incluído em sua grade curricular a disciplina Introdução à Saúde Coletiva, não há um enfoque específico desta temática em seu conteúdo. Sendo assim, os estudantes, ao término do curso de graduação em EF, evidenciam um déficit de conhecimento sobre suas açóes na área da saúde, especificamente dentro da ESF.

Entendemos que este curso deva favorecer as habilitaçóes de graduado em EF, oportunizando a formação inicial, no nível de graduação do Ensino Superior, de um profissional crítico e reflexivo, que possua um conhecimento amplo da área da Saúde/EF, associada ao contexto sóciohistórico-cultural e educacional do país. Um profissional que se caracteriza pela promoção e desenvolvimento de atitudes éticas, bem como da autonomia intelectual, criatividade e criticidade referentes ao conhecimento e atuação profissional, podendo intervir e transformar hábitos sociais que levem à prática da atividade física regular da população, com vistas à melhoria da qualidade de vida e obtenção de um estilo saudável de viver e bem estar. Uma formação que possa ensejar a realizaçáo de momentos de aproximação, constatação, co-atuação, atuação, reflexão e busca de transformação da realidade profissional, incentivando um exercício de formação para os mais diversificados campos de atuação da área.
Neste contexto, reforçamos como local para intervenção do profissional de EF a ESF, que surge como uma das alternativas de (re)orientação do modelo de atenção à saúde, e é entendido como resultante do estabelecimento de vínculos e a criação de laços de compromisso e co-responsabilidade entre os poderes políticos, os profissionais de saúde e a comunidade. A ESF é um caso exemplar na estruturação da atenção básica, por duas razóes: primeiro por destacar-se na Agenda Nacional de Saúde como instrumento de reforma da política de saúde brasileira que envolve mudanças no modelo de atenção, na organização do sistema de saúde e nas modalidades de alocação de recursos e de remuneração das açôes básicas de saúde, e segundo por acompanhar o recente foco das políticas sociais na família, que passa a ser sujeito de atenção, sobre o qual deve se ter pleno conhecimento de seus problemas (MENDONÇA e HEIMANN, 2006). A partir deste programa de governo, surge então, a oportunidade da EF explorar um espaço relativamente novo de atuação, e reforçar seu entendimento junto à sociedade e sua importância na defesa a saúde da população.

De acordo com as características organizacionais descritas pelo Ministério da Saúde (BRASIL, 2006), nota-se a proximidade da ESF, com a comunidade, esta particularidade demonstra um enorme potencial para estimular o aumento de pessoas fisicamente ativas em uma dada comunidade principalmente, no que aponta para um fácil acesso do indivíduo ao programa. Pontuamos ainda, que uma possível inserção do profissional de EF na ESF vem sendo um assunto muito discutido nos últimos anos, principalmente com o advento das criaçôes do Núcleo de Atenção Integral na Saúde da Família (NAISF) e posteriormente do Núcleo de Apoio a Saúde da Família (NASF).

Embora nesta área já existam alguns estudos sobre a inserção do profissional de EF na ESF, este assunto ainda tem muito a ser explorado pelas Secretarias de Saúde, vislumbrando uma futura efetivação deste profissional neste Programa. Atualmente observa-se poucos profissionais de EF atuando na ESF. Não conseguimos entender como o Brasil com tantos problemas de saúde, pode abrir mão de profissionais de áreas da saúde como: Educação Física, Fisioterapia, Nutrição, Fonoaudiologia, dentre outras, que estáo efetivamente inseridas na ESF. Estes profissionais, possivelmente acrescentariam em muito na qualidade dos serviços prestados a essas comunidades (VIEIRA, 2004; BRASIL, 2005; QUINT, 2005; BUCHABQUI, CAPP e PETUCO, 2005; FRAGA e WACHS, 2007; BRASIL, 2008).

Diante da necessidade da inserçáo efetiva do profissional de educação física na ESF, este estudo tem como objetivo desenvolver um CD interativo contendo a intervençáo do profissional de Educação Física nos programas de Hipertensão Arterial Sistêmica e Diabetes Mellitus na Estratégia Saúde da Família. 


\section{REVISÃO DA LITERATURA}

\section{Educação e Tecnologia}

Atualmente observamos através de estudos como Vieira (2001), Ferreira (2003), Da Costa e Cruz (2004) e Pedroso e Nascimento (2009), uma incessante procura por parte de educadores em geral na busca de novas possibilidades que melhorem a qualidade do ensino e otimizem o tempo do processo ensino - estudo - aprendizagem dos educandos em geral. Neste cenário, apontamos como uma realidade de nossa sociedade, os meios tecnológicos como vídeo, DVD, fitas, cinema, TV, CD - ROM, internet, fotos e outros que já há algum tempo são utilizados na contribuição de forma muito positiva aos resultados alcançados com alunos, independente de sexo, faixa etária e segmento.

Embora as dúvidas para utilização destes recursos no meio educacional surjam proporcionalmente ao crescimento destas ferramentas, observamos que por características próprias de nossa atual sociedade vale a pena nos esforçarmos quanto à busca de mais estudos que identifiquem tais problemas (dúvidas), como por exemplo, as diferentes formas de utilização da tecnologia no mundo escolar (FERREIRA, 2003). Ao ensinar através da tecnologia na educação, não podemos negar o poder que esta exerce nas pessoas; este fato é sem dúvida algo muito intrigante.

O uso do computador é um fenômeno mundial sendo utilizado frequentemente de várias formas para satisfazer os diversos objetivos, inclusive para fins pedagógicos. De acordo com Vieira (2001) e Ferreira (2003), esta ferramenta não se caracteriza como um fato novo; o uso deste recurso para educação ao longo das duas últimas décadas, já vem sendo muito explorado por parte dos professores como um meio para atingir seus fins influenciando a aprendizagem e o ensino. Ainda segundo Vieira (2001, p. 59) "*a tecnologia e os recursos audiovisuais, promovem a aprendizagem, e estes recursos estão a serviço do professor em sala de aula“. Ao mesmo tempo ressalta que para um melhor aproveitamento destes recursos precisamos qualificar melhor nossos docentes (VIEIRA, 2001).

$\mathrm{Na}$ fala do autor $o p$. cit., nota-se uma preocupação com os cuidados na preparação do profissional que irá utilizar estes recursos no meio educacional, este entâo prossegue em seu texto com a seguinte idéia: falta um treinamento e aperfeiçoamento para estes professores, aproximando-os ainda mais destas ferramentas e utilizando todas as suas possibilidades colaborando para estes em sua reflexão e na ação didática (VIEIRA, 2001).

Perrenoud (2000 in DA COSTA E CRUZ, 2004, p. 2), aborda esta questão de uma forma ainda mais preocupante:
Os professores que não souberem lidar com o avanço tecnológico serão vítimas de uma seleção natural, onde somente progredirão aqueles que construírem estas novas competências. Os professores que não quiserem envolver-se nisso (formação tecnológica) disporão de informaçôes científicas e de fontes documentais cada vez mais pobres, em relação àquelas às quais terão acesso seus colegas mais avançados.

Portanto, os educadores de uma forma geral deverão estar mais "conectados" à possibilidade de agregar valores educacionais para nossos alunos. Portanto segundo os estudos de Pedroso e Nascimento (2009), torna-se muito importante a utilização dos meios de comunicação e da tecnologia da informação voltados para o processo ensinoestudo-aprendizagem na EF. Em síntese, Vieira (2001, p. 59-60), destaca que:

a experiência visual do sujeito que aprende a partir de telas cintilantes, detectando, esquadrinhando e interpretando um ou mais estímulo presentes nas telas, retirando delas algum tipo de ensinamento, pode permitir uma mudança cognitiva mais ou menos duradoura. E por isso ele passa a "saber", "conhecer", "entender" e "lembrar".

Portanto, ao término deste estudo acreditamos estar colaborando para que o método de ensino utilizado possa levar educadores e educandos a trilhar na busca do conhecimento referente à EF na ESF.

\section{Treinamento Aeróbio (contínuo) e Alongamento (estático)}

O simples fato de ser ativo por si só, não garante melhor estado de saúde, em função de aspectos técnicos que devem ser observados na prescrição de exercício físico com autêntica supervisão profissional. Por sua vez, nossa proposta optou por prescrição e acompanhamento de dois modos de exercício físico; a caminhada e o alongamento, ambos já reconhecidos em sua contribuição e aplicabilidade em pessoas com reduzida aptidão física. Isto é particularmente verdadeiro quando a realização de procedimentos de avaliação antropométrico-funcional em populaçóes independente de seu grau de saúde (FERNANDES FILHO, 2003).

A indicação dessas duas modalidades está baseada em sua facilidade de execução, em seu baixo custo e por permitir que o participante execute a tarefa prescrita pelo profissional de EF mesmo na eventual ausência deste.

Os "elementos da aptidão física relacionada à saúde são a capacidade aeróbia, a flexibilidade/alongamento e a força/resistência muscular“ (ACSM, 2003, p. 39; KISS, 2003, p. 7). As duas primeiras são de extrema simplicidade 
em sua execução e são indicadas como proposta de exercício físico para pessoas que apresentem alguma limitação orgânico-funcional.

No caso da força/resistência muscular, sua execução requer a disponibilidade de recursos materiais de elevado custo e necessidade de maior complexidade de coordenação motora para que os participantes executem a rotina de exercícios físicos com bom nível de proficiência. Segundo ACSM (2003, p. 137), verificam-se recomendaçóes muito específicas para força/resistência muscular:

pois esta não é recomendada como forma primária de treinamento como exercícios para indivíduos hipertensos, não reconhecendo esta como fonte de extrema efetividade para baixar PA, principalmente quando se caracteriza por programas independentes.

Outro ponto merecedor de nota é a necessidade de acompanhamento de um profissional para iniciantes para garantia de segurança na tarefa a ser desempenhada nas máquinas para realização dos exercícios de força.

\section{Treinamento Aeróbio (contínuo)}

Segundo Monteiro (2004, p. 169) o treinamento contínuo caracteriza-se da seguinte forma:

O treinamento contínuo é executado em ritmo cadenciado e geralmente envolve intensidades de esforço, variando entre 50\% e 85\% do Volume Máximo de Oxigênio $\left(\mathrm{VO}_{2}\right.$ máx.). Em alguns casos, praticantes bem condicionados realizam seus trabalhos numa faixa que vai de $70 \%$ a $90 \%$ do $\mathrm{VO}_{2}$ máx.

Durante uma sessão de treinamento aeróbio, é comum observar variaçóes de intensidade, onde diferentes níveis de steady-state (estado de equilíbrio) são requeridos. Em função disso, este tipo de treinamento pode ser de alta, média ou baixa intensidade. Portanto, para indivíduos iniciantes, este treinamento é recomendável nas intensidades baixa e média. Essas taxas de esforço permitem a instalação de steady-state, e também são facilmente suportadas, reduzindo as possibilidades de desistência. (MONTEIRO, 2004)

Segundo Warburton e colaboradores (apud PINTO e DEMARZO, 2005, p. 23),

no geral, quanto mais elevada a intensidade da atividade, menor o tempo requerido para se ter benefícios para a saúde. Cada sessão aeróbia de exercício deve começar com um aquecimento (exercício leve, para se elevar gradualmente a frequência cardíaca e a temperatura corporal) e terminar com um período de recuperação (exercício leve, para se diminuir lentamente a freqüência cardíaca e a temperatura corporal após programa específico de exercícios).

A recomendação para realização do exercício físico com vistas a melhorar a aptidão cardio-respiratória preconiza que este "deva ser elaborado de forma a proporcionar uma melhora na capacidade da circulação central, bem como aprimorar a capacidade dos músculos em utilizar o oxigênio“" (MONTEIRO, 2004, p. 155).

Desse modo, a forma de realizaçáo dos exercícios deve ser de acordo com o nível de aptidão apresentado pelo executante, além da exigência para que a intensidade da caminhada seja dentro de parâmetros funcionais como o percentual do consumo máximo de oxigênio para que se garanta, por exemplo, a realização da atividade dentro de condiçôes de aerobiose suportáveis, condição conhecida como steadystate o que é imprescindível para pessoa acometidas por HAS, DM e obesidade..

Optamos por adotar o seguinte nível de intensidade quando da prescrição de exercícios aeróbios (WARBURTON e colaboradores, apud PINTO e DEMARZO, 2005) que deve ser adequado ao nível de aptidão de pessoas iniciantes na prática de qualquer programa de exercício físico com regularidade semanal.

\section{METODOLOGIA}

\section{Desenvolvimento do DVD interativo}

A concepção de aprendizagem utilizada baseou-se em estudos que proporcionam diretrizes para as áreas de desenho e eventos instrucionais (GAGNÉ, 1980). Considerando o tema abordado no software de importância não só para acadêmicos ou professores de EF, como também para os profissionais de EF que atuam na ESF, procuramos desenvolver o conteúdo de forma clara e simples. O CD interativo foi traduzido em uma mídia e construído utilizando-se uma adaptação do Modelo de três estágios para desenvolvimento de programas Computer-aid Instruction (PRICE, 1991) assim descritos: a). Planejamento inicial; b). Planejamento e desenvolvimento do conteúdo instrucional; c) Avaliação e revisão.

\section{Fase 1 - Planejamento inicial}

Esta fase consiste na base do projeto de desenvolvimento do CD, onde é caracterizado o público alvo, escolhido o tema a ser abordado, bem como são definidos os objetivos educacionais, os recursos disponíveis, o design instrucional e as técnicas de modelagem. Os objetivos educacionais 
foram definidos em termos de conteúdo, conhecimento e habilidades a serem adquiridos e organizados em tópicos e atividades para cada módulo. Para o desenvolvimento da multimídia foram consideradas as etapas de preparação dos conteúdos, elaboração do projeto gráfico, desenvolvimento da estrutura de navegação, testes/manutenção, implantação e projeto gráfico impresso para embalagem.

\section{Fase 2 - Planejamento e desenvolvimento do conteúdo instrucional}

Nessa fase foi realizada a reunião de todo o material bibliográfico, no sentido de organizá-lo em uma sequência lógica para a apresentação do conteúdo de forma clara e abrangente. Fizeram parte desse material, publicaçóes de pesquisas, materiais diversos preparados como conteúdo de aulas, materiais apresentados em eventos científicos, livros, artigos científicos e vídeos. Para compor o CD foi planejado o desenvolvimento de quatro módulos, a saber: I - Aspectos gerais para prescrição de treinamento aeróbio e alongamento; II - Aspectos específicos para prescrição de treinamento aeróbio; III - Alongamento e IV - Sugestão da rotina para o desenvolvimento específico do treinamento nas UBS.

\section{Fase 3 - Avaliação e revisão}

Para elaboração deste produto, não foi utilizada a terceira fase deste Modelo (avaliação e revisão) proposta por Gagné (1980).

\section{RESULTADOS}

O CD interativo foi desenvolvido em ambiente Windows com duas ferramentas: Power Point e Corel Draw. O Power Point é um programa utilizado para edição e exibição de apresentaçóes gráficas e foi desenvolvido pela Microsoft, já o Corel Draw é um programa de desenho vetorial bidimensional para design gráfico desenvolvido pela Corel Corporation, Canadá. $\mathrm{Na}$ edição dos textos externos ao software e composição dos esquemas iniciais do projeto foram utilizadas as ferramentas presentes na suite Microsoft Office versão 2003 Profissional. Para conversão dos arquivos no formato PDF utilizou-se software Adobe Acrobat Professional versão 7.0 com utilização de recursos de proteção de conteúdo. A distribuição do sistema foi feita por meio de mídia no formato CD-R que se mostrou mais adequada ao volume de dados. $\mathrm{O}$ mecanismo de funcionamento do sistema desenvolvido dispensa rotina de instalação. Todos os módulos necessários para seu pleno funcionamento são executados direta e automaticamente do CD não sendo necessária a cópia de arquivos para o disco rígido.
Como requisitos mínimos para execução do Sistema Multimídia recomenda-se um microcomputador com processador compatível com Pentium III, $800 \mathrm{MHz}$ ou AMD Athlon XP ou superior, $512 \mathrm{MB}$ de memória RAM, mínimo de $430 \mathrm{MB}$ de espaço livre no disco rígido, dispositivo leitor de CD-R, Sistema operacional Windows XP ou superior e software para leitura de arquivos em formato PDF.

Como mostra a Figura 1, o CD interativo é composto por uma tela de abertura, uma tela de apresentação, tela com o menu principal que leva às telas iniciais de cada um dos quatro módulos (HAS, DM, Obesidade e Protocolo) e várias telas onde o usuário poderá testar através de questóes objetivas, o que foi apreendido com os textos explicativos anteriores. Ao final, o usuário poderá calcular sua margem de acertos. Para sair do programa, basta acessar a tela de saída.

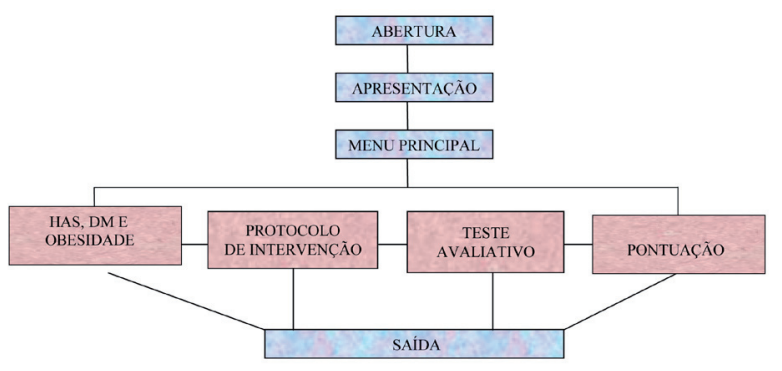

Fig 1. Estrutura do CD Atividade Física nos Programas de Hipertensão, Diabetes e Obesidade na Estratégia Saúde da Família

Foram utilizadas para a construção das interfaces, características como: disposição, tamanho e representatividade dos ícones, cores, equilíbrio de objetos dispostos na tela e demais pontos importantes para a obtenção de aplicaçóes com recursos visuais em nível aceitável de interatividade (PRICE, 1991; PRESSMAN, 1995). A tela de abertura do CD e a apresentação são feitas de forma automática em tempo sincronizado até o menu principal. Nessa tela, o usuário poderá acessar todo o conteúdo que compóe o CD-ROM como apresentação, textos de apoio, referência bibliográfica e exercícios clicando sobre os botóes correspondentes.

No que se refere às questóes propostas com enfoque no protocolo proposto neste estudo, o usuário poderá avaliar seus conhecimentos adquiridos e, suas respostas, recebem feedback, oferecendo oportunidade de saber se estavam corretas ou não.

\section{CONSIDERAÇÓES FINAIS}

Entendemos que o produto Atividade Física nos Programas de Hipertensáo Arterial Sistêmica e Diabetes Mellitus na Estratégia Saúde da Família, desenvolvido nesse estudo e, tem por finalidade ratificar a necessidade 
deste profissional na ESF. Trata-se de uma ferramenta pedagógica de fixação que busca aproximar o acadêmico de EF ao cenário da Saúde Coletiva, através de informaçôes fundamentais sobre as intervençóes deste profissional na ESF.

Acreditamos que a utilização de mídia digital para a aprendizagem no ensino das ações desenvolvidas pelo profissional de EF na saúde coletiva, seja uma estratégia, que por ser inovadora, necessita ser mais desenvolvida, além de demandar maiores esforços nessa direção. Portanto, o produto desenvolvido será distribuído não só ao professor da disciplina Introduçáo à Saúde Coletiva, assim como a todos os docentes do Curso de EF e os discentes que se interessarem por esta temática.

\section{REFERÊNCIAS}

1. AMERICAN COLLEGE OF SPORTS MEDICINE. Diretrizes do ACSM para os testes de esforço e sua prescriçáo. 6. ed. Rio de Janeiro: Guanabara Koogan, 2003.

2. BAGRICHEVSKY, Marcos et al. A Saúde em Debate na Educação Física. BLUMENAU, SC: Edibes, 2003.

3. BUCHABQUI, Jorge Alberto; CAPP et al. Convivendo com Agentes de Transformaçáo: a interdisciplinaridade no processo de ensino/aprendizado em saúde. 2005. 7 f. Ensaio. - Revista Brasileira de Educação Médica. Associação Brasileira de Educação Médica, Rio de Janeiro, 2005.

4. BRASIL. 1.065/GM de 04 de julho de 2005. Cria Núcleos de Apoio Integral na Saúde da Família. Ministério da Saúde, Brasília - DF, 2005.

5. - Ministério da Saúde. Secretaria de Atenção à Saúde. Departamento de Atenção Básica. Política Nacional de Atençáo Básica / Ministério da Saúde, Secretaria de Atenção à Saúde, Departamento de Atenção à Saúde. - Brasília: Ministério da Saúde, 2006.

6. . Portaria n ${ }^{0} 154$ de 24 de janeiro de 2008. Cria os Núcleos de Apoio à Saúde da Família. Ministério da Saúde, Brasília - DF. 2008.

7. DA COSTA, Chiara Lívia; CRUZ, Dulce Márcia. Mídia Digital no Apoio ao Ensino Presencial. 2004. 8 f. Artigo. - Curso de comunicação Social. Universidade Regional de Blumenau, 2004, Curitiba.
8. FERNANDES, FILHO, José. A Prática da Avaliaçáo Funcional. 2.ed. Rio de Janeiro: Shape, 2003.

9. FERREIRA, José Heleno. Integraçáo, Tecnologia e Sociedade. 2003. 6 f. Artigo. - http://www2.funedi.edu.br/revista/revista-eletronica3/artigo6-3.htm acesso em: 17/11/2009.

10. FRAGA, Alex Branco; WACHS, Felipe (orgs). Educaçáo Física e Saúde Coletiva: políticas de formação e perspectivas de intervenção. Porto Alegre: Editora da UFRGS, 2007.

11. GAGNÉ, Robert Mills. Princípios Essenciais da Aprendizagem para o Ensino. Trad. de Rute V. Ângelo. Porto Alegre (Brasil): Ed. Globo, 1980.

12. KISS, Maria Augusta Peduti Dal'Molim. Esporte e Exercício: avaliação e prescrição. São Paulo: Roca, 2003.

13. MENDONÇA, Maria Helena Magalhães; HEIMANN, Luiza Sterman. A trajetória da Atenção Básica em Saúde e do Programa Saúde da Família no SUS: uma busca de identidade. In: Lima, N.T. organizadores. Saúde e Democracia: história e perspectivas do SUS. Rio de Janeiro: ed. Fiocruz; p. 481-502, 2006.

14. MONTEIRO, Walace Davi. Personal Training MANUAL PARA AVALIAÇÃO E PRESCRIÇÃO DE CONDICIONAMENTO FÍSICO. Rio de Janeiro, $4^{0}$ ed.: Sprint, 2004.

15. PEDROSO, Bruno; NASCIMENTO, Ronaldo José. Aplicaçáo das Tecnologias da Informaçáo e Comunicaçáo no Processo Ensino-Aprendizagem do Handebol. 2009. 9 f. - PPGECT / Programa de PósGraduação em Ensino de Ciência e Tecnologia. Universidade Tecnológica Federal do Paraná, Paraná, 2009.

16. PINTO, Maria Eugênia Bresolin; DEMARZO, Marcelo Marcos Piva. Atividade Física na Atençáo Primária à Saúde. 2005. 39 f. Artigo. - Promef / Organizado pela Sociedade Brasileira Medicina de Família e Comunidade. Porto Alegre: ed Artmed/Panamericana, 2005.

17. PRESSMAN, Roger S. Engenharia de Software. Trad. de José Carlos Barbosa dos Santos. São Paulo (Brasil): Makron Books, 1995. 
18. PRICE, Robert V. Computer-aid Instruction: a guide for authors. Pacific Grove (EUA): Brooks/ Cole Publishing Co, 1991.

19. VIEIRA, Edimar Teixeira. O Programa Saúde da Família sob o Enfoque dos Profissionais de Saúde. Fortaleza, CE, 2004. Disponível em: https://www.unifor. br/hp/doc.noticias/vol17-artigo3.pdf. Acesso em: 20 set. 2007.

20. VIEIRA, Sérgio Lontra. Telas que Ensinam: mídia e aprendizagem. Do cinema ao computador. 2. ed. Campinas: Editora Alínea, 2001. 